\title{
Effects of a multi-herbal extract on type 2 diabetes
}

\author{
Jiyoung Yeo, Young-Mi Kang, Su-In Cho, Myeong-Ho Jung*
}

\begin{abstract}
Background: An aqueous extract of multi-hypoglycemic herbs of Panax ginseng C.A.Meyer, Pueraria lobata, Dioscorea batatas Decaisne, Rehmannia glutinosa, Amomum cadamomum Linné, Poncirus fructus and Evodia officinalis was investigated for its anti-diabetic effects in cell and animal models.
\end{abstract}

Methods: Activities of PPARy agonist, anti-inflammation, AMPK activator and anti-ER stress were measured in cell models and in $d b / d b$ mice (a genetic animal model for type 2 diabetes).

Results: While the extract stimulated PPARy-dependent luciferase activity and activated AMPK in C2C12 cells, it inhibited TNF- $\alpha$-stimulated IKK $\beta / N F k B$ signaling and attenuated ER stress in HepG2 cells. The $d b / d b$ mice treated with the extract showed reduced fasting blood glucose and $\mathrm{HbA}_{1 c}$ levels, improved postprandial glucose levels, enhanced insulin sensitivity and significantly decreased plasma free fatty acid, triglyceride and total cholesterol.

Conclusion: The aqueous extract of these seven hypoglycemic herbs demonstrated many therapeutic effects for the treatment of type 2 diabetes in cell and animal models.

\section{Background}

Caused by complex interactions of multiple factors, diabetes mellitus type 2 (type 2 diabetes) is characterized by decreased secretion of insulin by the pancreas and resistance to the action of insulin in various tissues (eg muscle, liver, adipose), leading to impaired glucose uptake [1]. Management of type 2 diabetes usually begins with change of diet and exercise [2] and most patients ultimately require pharmacotherapy, such as oral anti-diabetic drug (OAD) [1]. OADs include sulfonylurea, non-sulfonylurea secretagogues, biguanides (eg metformin), thiazolidinediones (eg TZD or glitazone) and glucosidase inhibitors and glucagon-like peptide-1 (GLP-1) inhibitor. All OADs, however, have adverse effects, eg weight gain with sulfonylurea, non-sulfonylurea secretagogues or TZD, edema and anemia with TZD [1].

A variety of medicinal herbal products including herbs used in Chinese medicine have beneficial effects on diabetes [3] and used as non-prescription treatment for diabetes [4]; many of these herbs have been formulated into multi-herbal preparation for enhanced effects [5].

\footnotetext{
* Correspondence: jung0603@pusan.ac.kr

School of Korean Medicine, Pusan National University, Beomeo-ri, Mulguemeup, Yangsan, Gyeongsangnam-do, 626-770, South Korea
}

While traditional formulae are often prescribed, their efficacy has yet to be investigated; recently, anti-diabetic multi-herbal formulae were studied and reported [6,7].

The present study reports a new anti-diabetic formula consisting of seven herbs, namely hypoglycaemic cadidates including Panax ginseng C.A.Meyer, Pueraria lobata, Dioscorea batatas Decaisne, Rehmannia glutinosa [8], Amomum cadamomum Linné [9], Poncirus fructus [10] and Evodia officinalis [11] which are available in South Korea. This formula's anti-diabetic molecular mechanisms and anti-hyperglycemic effects are demonstrated in cell models and $d b / d b$ mice respectively.

\section{Methods}

\section{Extract preparation}

The dried herbs of Panax ginseng C.A. Meyer (Aralia family), Pueraria lobata (Pea family), Dioscorea batatas DECAISNE (Dioscoreaceae), Rehmannia glutinosa (Phrymaceae), Amomum cadamomum Linné (Zingiberaceae), Poncirus fructus(Rhamnaceae)) and Evodia officinalis DODE(Rutaceae) were purchased from Kwangmyungdang Natural Pharmaceutical (Korea) and identified morphologically, histologically and authenticated by Professor Su-In Cho (School of Korean Medicine, Pusan

\section{Biomed Central}


National University, Korea) according to standard protocol in National Standard of Traditional Medicinal Materials of The Korean Pharmacopeia [12]. Voucher specimens of all seven species were deposited in Pusan National University, Korea.

Powders of the herbs were mixed in equal amount (200 g each) and extracted in hot-water. The extract was freeze dried to powder and melt by dimethylsulfoxide (DMSO) when used. Macelignan, an active compound of Myristica fragrans Houtt (Myristicaceae), was prepared for positive control [13].

\section{Cell lines}

Cell lines of human embryonic kidney (HEK) 293 (CRL1573), 3T3-L1 pre-adipocytes (CL-173), HepG2 hepatocytes (HB-8065) and C2C12 skeletal myoblast cells (CRL-1772) were obtained from the American Type Culture Collection (ATCC, USA). HEK293 and HepG2 were cultured in Dulbecco's modified Eagle's medium (DMEM) containing glucose (Invitrogen, USA) supplemented with $10 \%(\mathrm{v} / \mathrm{v})$ fetal bovine serum (Gibco BRL, USA). The 3T3-L1 pre-adipocytes were differentiated as described previously [14]. $\mathrm{C}_{2} \mathrm{C}_{12}$ skeletal myoblast cells were grown in DMEM supplemented with $2 \%$ horse serum to induce differentiation into myotubes.

\section{Reporter assays}

The PPAR ligand-binding activity was measured with a GAL4/PPAR chimera assay and PPRE-tk-Luc reporter assay as described previously [15]. HEK293 cells were transfected with pFA-PPAR $\gamma$ and pFR-Luc (UAS-Gal4luciferase) and treated with the extract, rosiglitazone (Alexis Biochemicals, USA) or macelignan at doses ranging from 2 to $10 \mu \mathrm{mol} / \mathrm{L}$ for 24 hours. For PPRE-tkLuc reporter assay, HepG2 $\left(2 \times 10^{5}\right.$ cells/well $)$ were transfected with PPRE-tk-Luc and incubated with the extract, rosiglitazone or macelignan for 24 hours. The luciferase activities were then determined with a luciferase assay system kit (Promega, USA).

To determine the anti-inflammatory activities and anti-endoplasmic recticulum (ER) stress, we transfected HepG2 cells $\left(2 \times 10^{5}\right.$ cells/well) with NFkB-Luc reporter or ERSE-Luc reporter using a CignalTM Reporter Assay kit (SABiosciences, USA). The cells were then incubated with the extract, rosiglitazone or macelignan for 24 hours. The luciferase activities were determined with a Dual-Glo Luciferase assay system kit (Promega, USA).

\section{Real-time RT-PCR}

We performed Real-time RT-PCR to determine the expression of adipose fatty acid-binding protein (aP2), acyl-CoA synthetase (ACS) and carnitine palmitoyltransferase-1 (CPT-1). The total RNA was extracted with TRIzol reagent (Invitrogen, USA) and subjected to reverse transcription with M-MLV Reverse Transcriptase (Promega, USA). The total RNA was then amplified (with gene-specific primers) and quantified with a fluorescence thermocycler (iQ ${ }^{\mathrm{TM}} 5$, Multicolor Real-Time PCR System, Bio-Rad, USA).

\section{Western blot analysis}

Total proteins were extracted with PRO-PREP reagent (iNtRON Biotechnology, Korea) and immuno-blotted with the antibodies of p-AMPK, IkB $\alpha$, GRP78 or p-elf $2 \alpha$ (Santa Cruz Biotechnology, USA) [15]. The immune complexes were identified with an enhanced chemiluminescence detection system (Amersham Biosciences, Sweden) according to the manufacturer's instructions and in conjunction with a Fluorochem gel image analyzer (MFChem:BIS 3.2, Alpha Innotech, USA).

\section{Animal study}

Twenty-eight (28) male C57BL/KsJ- $d b / d b$ mice aged 8 weeks were purchased from Jackson Laboratory (USA) and individually housed in polycarbonate cages under a 12-hour light-dark cycle at $21-23^{\circ} \mathrm{C}$ and $40-60 \%$ humidity. After a 2-week adaptation period, the body weight and fasting blood glucose level of the 10-week-old mice were measured. Then, the mice were equally divided into four groups $(n=7)$ : (1) diabetic control, (2) rosiglitazone, (3) macelignan and (4) treatment (with the extract). All groups were fed a standard AIN-76 semisynthetic diet (American Institute of Nutrition) and three experimental groups (rosigltiazone, macelignan and treatment) were orally administered with rosiglitazone (10 mg/kg body weight), macelignan (15 mg/kg body weight) or the extract ( $150 \mathrm{mg} / \mathrm{kg}$ body weight) for three weeks. After starved for 12 hours, the mice were anesthetized with ether and their blood samples were collected from the inferior vena cava for the measurement of the blood and plasma biomarkers such as $\mathrm{HbA}_{1 \mathrm{c}}$ and insulin. All animal handlings during the experiments were in accordance with the Pusan National University guidelines for the care and use of laboratory animals.

\section{Fasting blood glucose, blood $\mathrm{HbA}_{1 \mathrm{c}}$ and plasma biomarker analyses}

During the experiments, the fasting blood glucose concentration was monitored by a Glucometer (GlucoDr, Allmedicus, Korea) with venous blood drawn from the mouse tail vein after a 12-hour fast. Moreover, the blood glycosylated hemoglobin $\left(\mathrm{HbA}_{1 \mathrm{c}}\right)$ collected from sacrificed mice was measured with a MicroMat ${ }^{\mathrm{TM}}$ II Hemoglobin $\mathrm{A}_{1 \mathrm{c}}$ Test (Bio-Rad Laboratories, USA). All blood samples obtained were centrifuged at $1000 \times g$ for $15 \mathrm{~min}$ at $4^{\circ} \mathrm{C}$ for biochemical analysis. The plasma insulin, glucagon and C-peptide levels were measured 
with the enzyme-linked immunosorbent assay (ELISA) kits (ALPCO Diagnostics, USA).

Furthermore, the plasma lipids such as total cholesterol and triglyceride were determined with commercial kits (Sigma-Aldrich, USA) while the plasma free fatty acid (FFA) concentration was determined with an ACS (acyl-CoA synthetase)-ACOD(ascorbate oxidase) method (Wako Pure Chemical Industries, Japan).

\section{Intraperitoneal glucose tolerance test (IPGTT) and intraperitoneal insulin tolerance test (IPITT)}

On the third week of treatment, an intraperitoneal glucose and insulin tolerance test (IPGTT and IPITT) were performed on all $d b / d b$ mice after a 12-hour overnight fast. To determine the glucose and insulin tolerance, we injected the mice intraperitoneally with glucose $(0.5 \mathrm{~g} /$ $\mathrm{kg}$ body weight) or insulin ( 2 unit/ $\mathrm{kg}$ body weight). The glucose concentrations of blood drawn from the tail vein were determined immediately upon collection at
30, 60 and 120 min after glucose injection or at 30, 60 and $120 \mathrm{~min}$ after insulin injection.

\section{Statistical analysis}

All statistical tests were two-sided, and the level of significance was set at 0.05 . All data are presented as mean \pm standard deviation (SD) for all groups. Statistical analyses were performed with the SPSS, version 18 (SPSSInc., Chicago, IL, USA). One-way ANOVA(analysis of variance) with post-hoc test by Duncan's multiplerange test was used to examine differences among groups. The data were analyzed by Student's t-test for two group comparison.

\section{Results}

\section{Effect on PPAR $\gamma$ agonist}

To determine if the extract was a PPAR $\gamma$ agonist, we searched the cell-based GAL4/PPAR chimera transactivation in Hek293 cells. As shown in Figure 1A, the
A

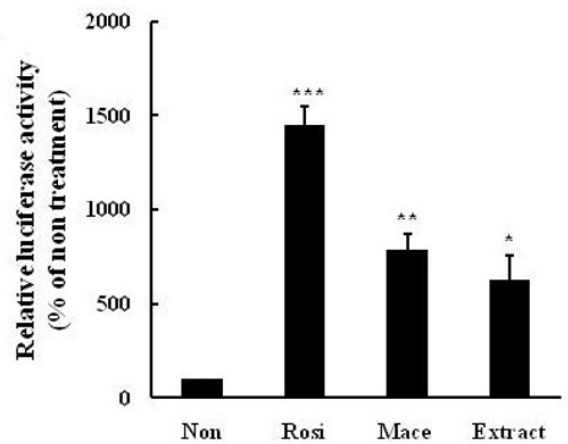

$\mathrm{C}$
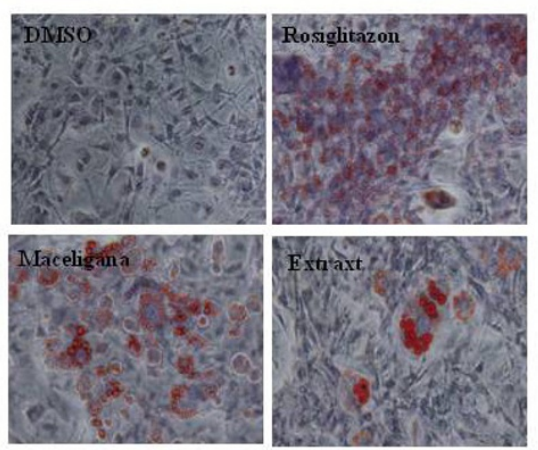

B

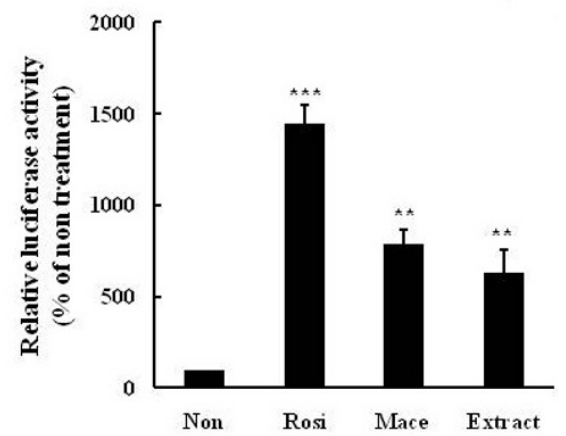

D

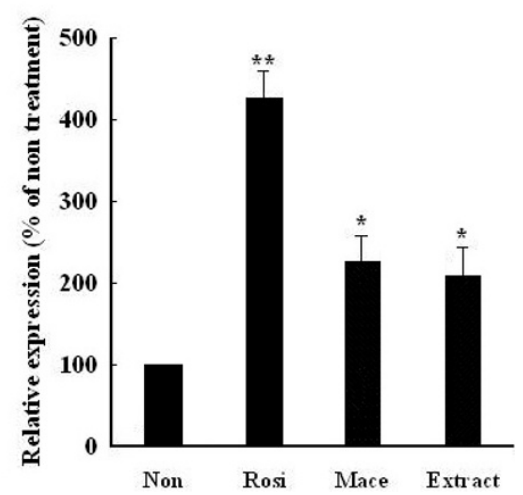

Figure 1 Extract functions as a PPAR $\gamma$ agonist. (A) Extract increased the ligand-binding activity of PPAR $\gamma$. HEK293 cells were transfected with pFA-PPAR $\gamma$ and pFR-Luc (UAS-Gal4-luciferase) and then treated with extract $(5 \mu \mathrm{g} / \mathrm{ml})$, rosiglitazone $(10 \mu \mathrm{M})$, or macelignan $(10 \mu \mathrm{M})$ for 24 hours. (B) Extract induced transcriptional activity of PPAR $\gamma$. Differentiated 3T3-L1 adipocytes were transfected with $3 \times$ PPREs-tk-Luc and treated with extract $(5 \mu \mathrm{g} / \mathrm{ml})$, rosiglitazone $(10 \mu \mathrm{M})$, or macelignan $(10 \mu \mathrm{M})$ for 24 hours. (C) Extract induced adipogenesis. Oil red $\mathrm{O}$ staining was measured after differentiation of 3T3-L1 cells in medium containing $0.1 \%$ DMSO (control), extract $(5 \mu \mathrm{g} / \mathrm{ml})$, rosiglitazone $(1 \mu \mathrm{M})$, or macelignan $(10 \mu \mathrm{M})$ for seven days. (D) Extract increased PPARy target gene (aP2) expression in 3T3-L1 adipocytes. Differentiated 3T3-L1 cells were treated with extract (5 $\mu \mathrm{g} / \mathrm{ml})$, rosiglitazone $(10 \mu \mathrm{M})$, or macelignan $(10 \mu \mathrm{M})$ for 24 hours. Expression of mRNAs was estimated using quantitative real-time RT-PCR, and the results were expressed as mRNA levels relative to $0.1 \%$ DMSO (control). Data represent are shown as mean \pm SD of three independent experiments $\left({ }^{*} P<0.05,{ }^{* *} P<0.01,{ }^{* * *} P<0.001\right)$. 
extract increased the PPAR $\gamma$-dependent luciferase activity $(P=0.035 v s$ non-treatment) similar to that of rosiglitazone $(P=0.001 v s$ non-treatment), a well-known PPAR $\gamma$ agonist, and macelignan ( $P=0.005 v s$ non-treatment), a PPAR $\alpha / \gamma$ dual agonist used as positive control throughout the experiments. To further explore the PPAR $\gamma$ agonist potential of the extract, transient transfections were performed in differentiated 3T3-L1 adipocytes with the tk-luciferase vector containing PPAR-responsive elements (PPREs) and then treated with the extract. The treatment stimulated PPRE-dependent luciferase activities in transfected cells $(P=0.005 v s$ non-treatment $)$ (Figure 1B). To provide biological evidence that the extract is a PPAR $\gamma$ ligand, we investigated adipocyte differentiation and expression of the adipocyte marker gene in 3T3-L1 cells treated with the extract. The treatment led to a significant increase in the formation of lipid droplets in similar to rosiglitazone and macelignan (Figure 1C). Moreover, the extract increased the expression of adipose fatty acid-binding protein $(\mathrm{aP} 2)(P=0.042 \mathrm{vs}$ non-treatment) (Figure 1D). Taken together, these results demonstrated that the extract was a PPAR $\gamma$ agonist.

\section{Effect on AMPK activation}

To determine if the extract mediated the AMP-activated protein kinase (AMPK) activation, we measured the
AMPK phosphorylation and expression of fatty acid oxidation genes in $\mathrm{C}_{2} \mathrm{C}_{12}$ cells incubated with the extract. As with the AMPK activator, aminoimidazole-4-carboxamide-1- $\beta$-d-ribofuranoside (AICAR) $(P=0.001$ vs nontreatment), the treatment activated $A M P K$ in $C_{2} C_{12}$ cells $(P=0.007 v s$ non-treatment), similar to when samples were treated with macelignan $(P=0.042$ vs nontreatment) (Figure 2A). Consistent with the results of AMPK phosphorylation, the treatment increased the expression of acyl-CoA synthetase (ACS) $(P=0.048 v \mathrm{~s}$ non-treatment) and carnitine palmitoyltransferase- 1 (CPT-1) $(P=0.041$ vs non-treatment) (Figure $2 \mathrm{~B})$, suggest that the extract activated AMPK.

\section{Effect on inflammatory processes}

As inflammatory processes play potential roles in the pathogenesis of insulin resistance, we investigated whether the extract possessed anti-inflammatory effects, including the inhibitory effects of the extract on IKK $\beta$ / NFkB signaling in HepG2 cells treated with TNF- $\alpha$ using NFkB response element containing reporter. While TNF- $\alpha$ treatment increased the NFkB-dependent luciferase activity $(P=0.001 v s$ non-treatment), The extract effectively prevented this increase $(P=0.034 \mathrm{vs}$ TNF- $\alpha$ treatment) (Figure 3A). Furthermore, the extract increased the IkB $\alpha$ level reduced by TNF- $\alpha$ treatment,

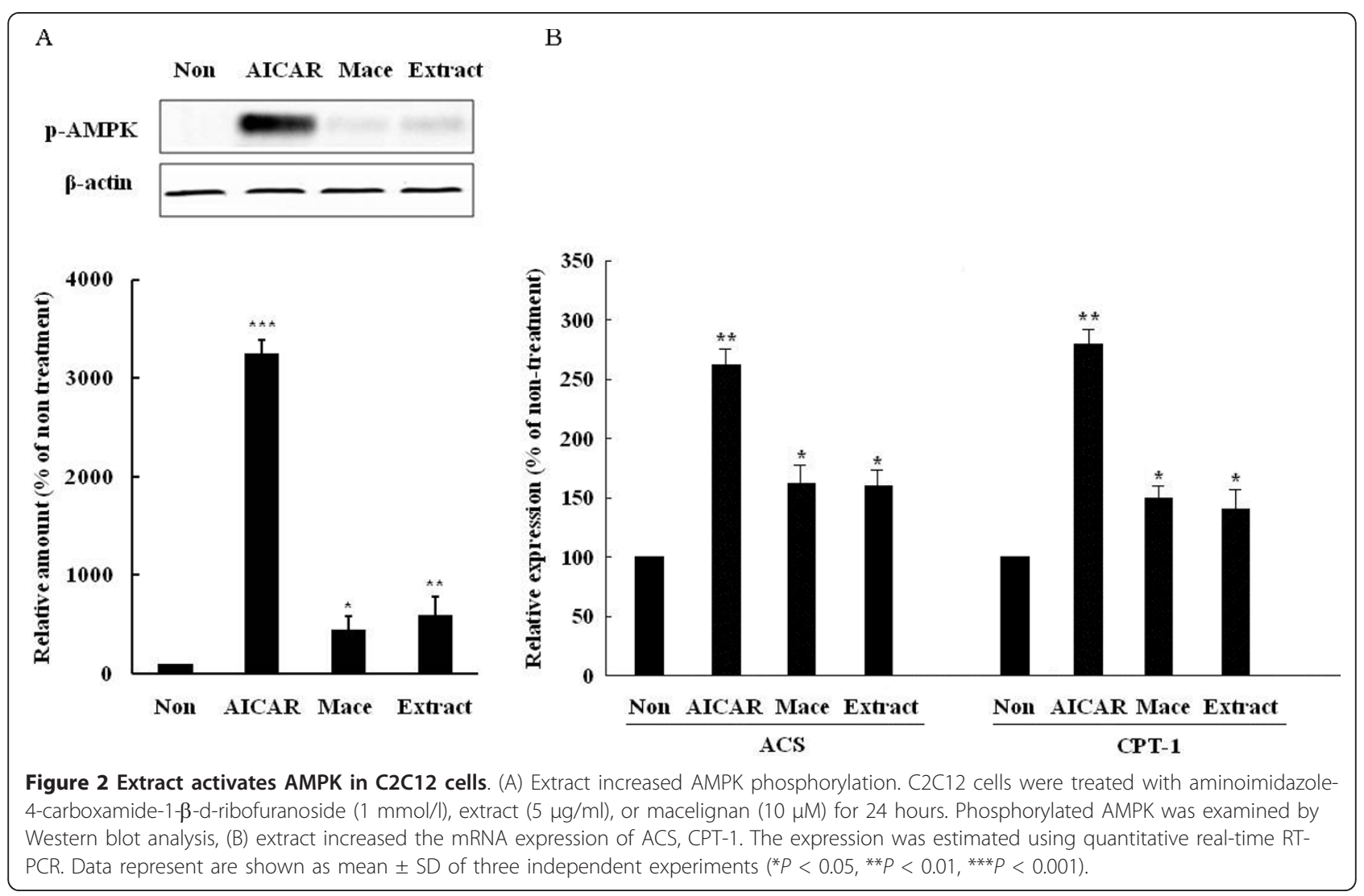




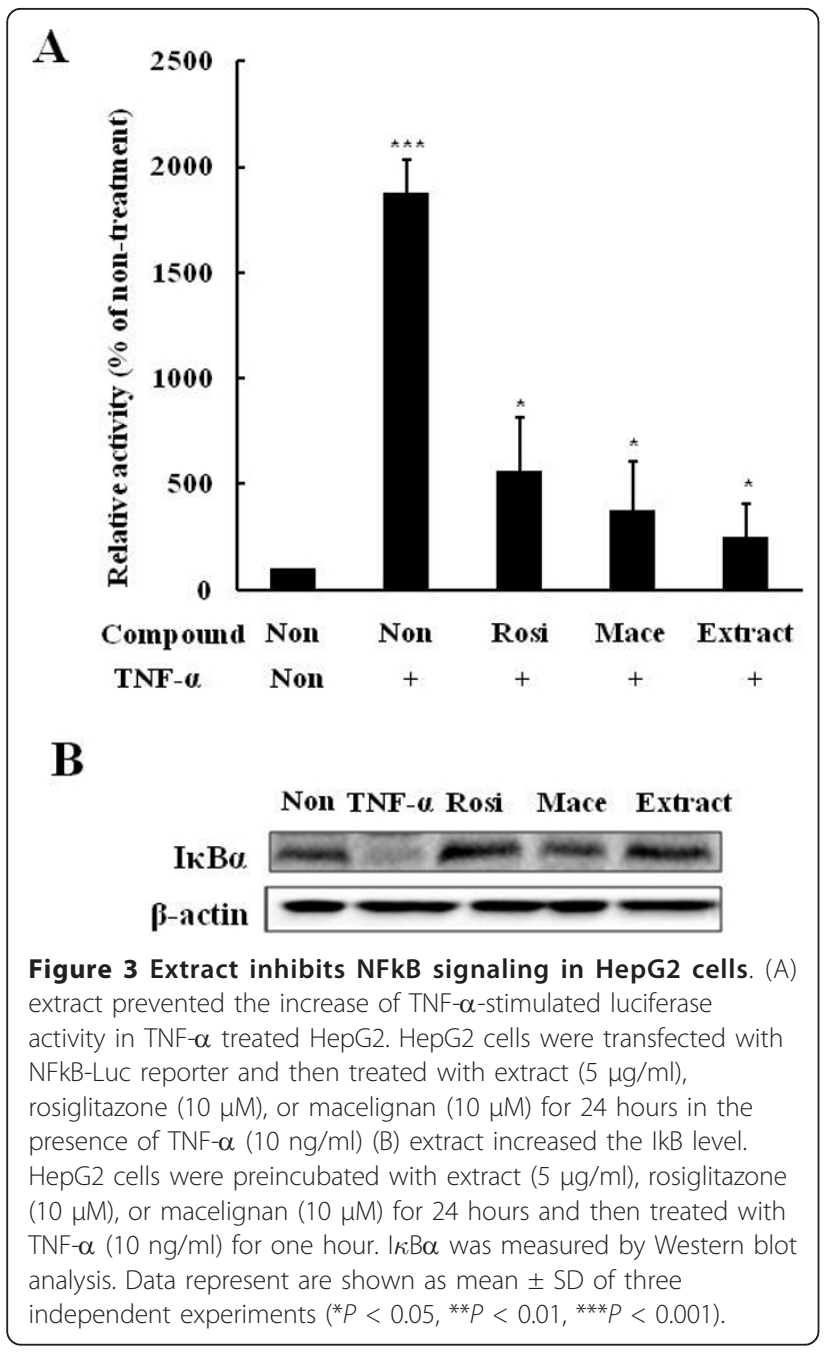

which was consistent with rosiglitazone and macelignan (Figure 3B). These results indicated that the extract exerted anti-inflammatory effects.

\section{Effect on attenuation of ER stress}

It has been recently suggested that ER stress plays a central role in the development of insulin resistance and diabetes by impairing insulin signaling through c-Jun $\mathrm{NH}_{2}$-terminal kinase (JNK) activation [16]. Therefore, we investigated whether the extract inhibited ER stress. We first examined the inhibitory effects on the luciferase activity of ERSE response element containing reporter in HepG2 cells treated with the ER stress inducer, thapsigargin. While thapsigargin treatment increased the ERSE-dependent luciferase activity $(P=0.001 \mathrm{vs}$ nontreatment), the extract effectively blocked the thapsigargin-mediated stimulation $(P=0.039 v s$ thapsigargin treatment) (Figure 4A). When ER stress indicators such as GRP78 and p-elF2 $\alpha$ were examined in thapsigargintreated HepG2 cells, Treatment by the extract suppressed the increase of the indicators by thapsigargin $(P=0.045 v s$ thapsigargin treatment) (Figure 4B). Taken together, these results demonstrated that the extract exerted protective effects against ER stress.

\section{Effects on body weight change and fasting blood glucose} in $\mathrm{db} / \mathrm{db}$ mice

To examine the in vivo anti-diabetic effects of the extract on diabetes, we orally administered rosiglitazone $(10 \mathrm{mg} / \mathrm{kg})$, macelignan $(15 \mathrm{mg} / \mathrm{kg})$ and the extract $(150$ $\mathrm{mg} / \mathrm{kg}$ ) to $\mathrm{C} 57 \mathrm{BL} / \mathrm{Ks}$ - $d b / d b$ mice every day for three weeks and the extract's effects were compared with rosiglitazone and macelignan. Treatment with the extract did not have a significant effect on the body weights in the $d b / d b$ mice; however, mice treated with rosiglitazone had final body weights significantly higher than those of the others $(P=0.001 v s$ control) (Figure 5A). The baseline (day 0) fasting blood glucose levels did not differ between groups; however, at the end of the experiment, the values of the extract-treated group were significantly lower compared to the diabetic control group $(P=$ $0.022 v s$ control) and so did the other groups treated with rosiglitazone $(P=0.001$ vs control) and macelignan $(P=0.002$ vs control). The blood glucose levels of the extract-treated mice were significantly reduced by about $15 \%$ compared to the control (Figure $5 \mathrm{~B}$ ).

\section{Effects on postprandial glucose and insulin sensitivity in $\mathrm{db} / \mathrm{db}$ mice}

To assess glucose homeostasis and insulin sensitivity in $\mathrm{db} / \mathrm{db}$ mice treated with the extract, we performed glucose tolerance and insulin tolerance tests before the end of the experiment. As shown in Figure 6A, the extract significantly reduced the blood glucose levels $(P=0.001$ $v s$ control $)$ similar to rosiglitazone $(P=0.003$ vs control $)$ and macelignan $(P=0.004$ vs control) used as positive controls compared with the diabetic control groups. The insulin tolerance test also showed that reduction in blood glucose levels in response to insulin was much greater in mice treated with the extract than in untreated $d b / d b$ mice $(P=0.002 v s$ control) (Figure $6 \mathrm{~B}$ ). These findings indicate that treatment with the extract affected not only regulation of the postprandial glucose level, but also enhanced the insulin sensitivity.

\section{Effects on plasma lipids in $\mathrm{db} / \mathrm{db}$ mice}

Effects of the extract on plasma triglycerides and FFAs levels and total cholesterol were investigated. Specifically, treatment with the extract significantly decreased the plasma free fatty acid $(P=0.021 v s$ control), triglyceride $(P=0.012$ vs control $)$ and total cholesterol $(P=$ $0.003 v s$ control) concentrations of the diabetic control $d b / d b$ mice compared with untreated $d b / d b$ mice when the experiment ended (Table 1). As lipolysis and 


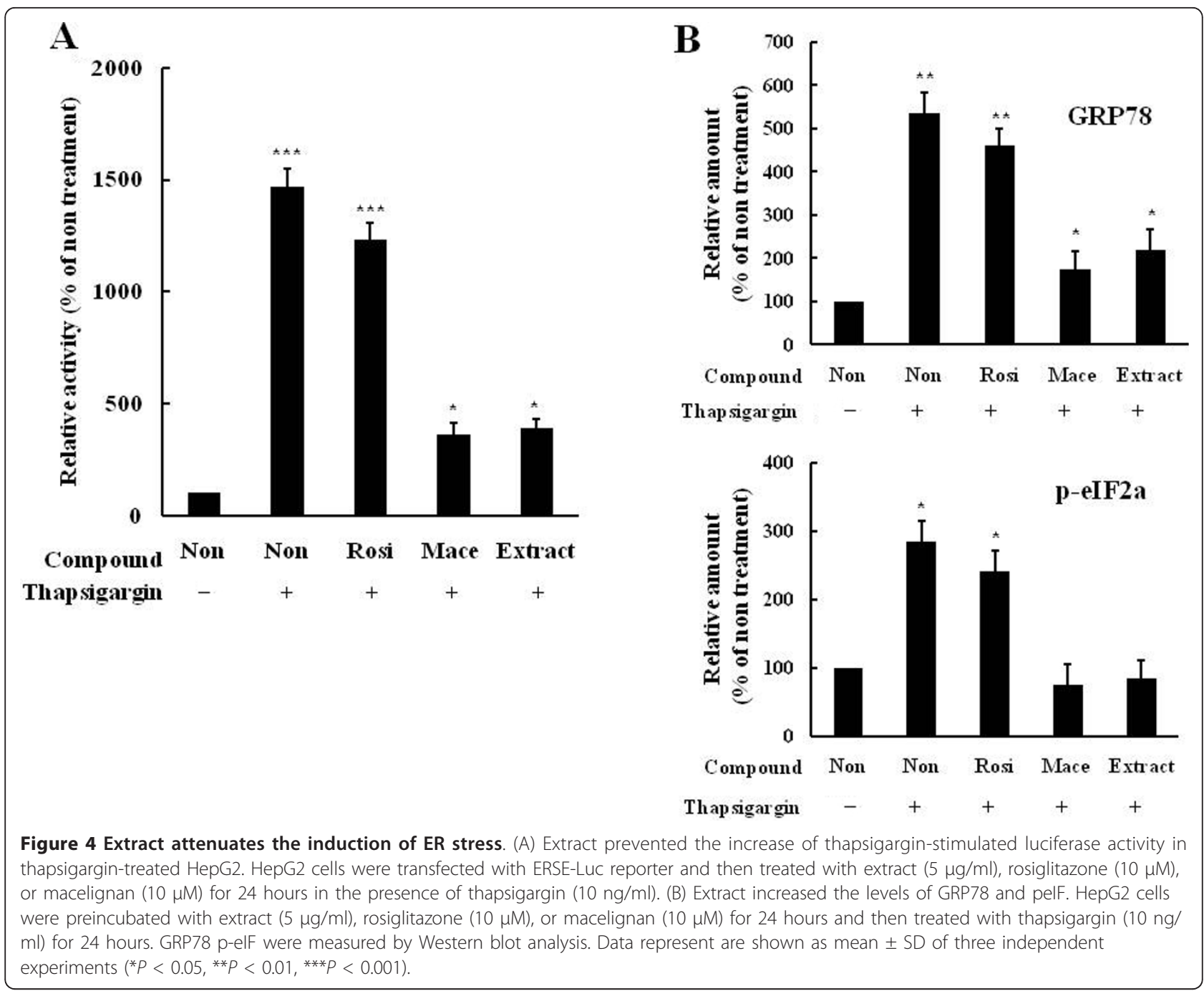

circulating free fatty acids increase under insulin resistance conditions, these results demonstrate that the decrease in plasma lipids may contribute to the improvement of severe diabetes, at least partially.

\section{Effects on glycosylated hemoglobin level and plasma biomarkers in $\mathrm{db} / \mathrm{db}$ mice}

Mice receiving the treatment with the extract showed a significantly lower blood glycosylated hemoglobin level compared to the diabetic control $d b / d b$ mice $(P=0.002$ $v s$ control). Both the plasma insulin $(P=0.042$ vs control) and C-peptide levels $(P=0.038 v s$ control $)$ were significantly higher in the extract-treated $d b / d b$ mice than in the diabetic control $d b / d b$ mice; however, the glucagon levels were significantly lower than those of the diabetic control $d b / d b$ mice ( $P=0.018 v s$ control). Therefore, treatment with the extract significantly improved the ratio of insulin/glucagon (I/G) when compared to the diabetic control $d b / d b$ mice (Table 2).

\section{Discussion}

In this study, we tested a formulation of seven medicinal herbs including Panax ginseng C.A.Meyer for the antidiabetic effects in cells and in vivo. We found that the extract from the seven herbs functioned as PPAR $\gamma$ agonists and an AMPK activators, as well as inhibitors of inflammation and ER stress. PPAR $\gamma$ can improve insulin sensitivity and glucose tolerance by regulating lipid storage, glucose homeostasis and adipokine regulation [17]. The TZD group, especially rosiglitazone and troglitazone, are agonists of PPAR $\gamma$ [18]. The extract significantly increased the PPAR $\gamma$-dependent luciferase activity in vitro and stimulated the formation of lipid droplets and the expression of aP2 upon transient transfection of 3T3L1 cells. Rb1, the most abundant ginsenoside in ginseng root, increases the expression of mRNA and protein of PPAR $\gamma$ and exerts anti-diabetic and insulin-sensitizing activities [19]. 20(S)-protopanaxatriol (PPT), a ginsenoside metabolite, increases PPAR $\gamma$-transactivation activity 


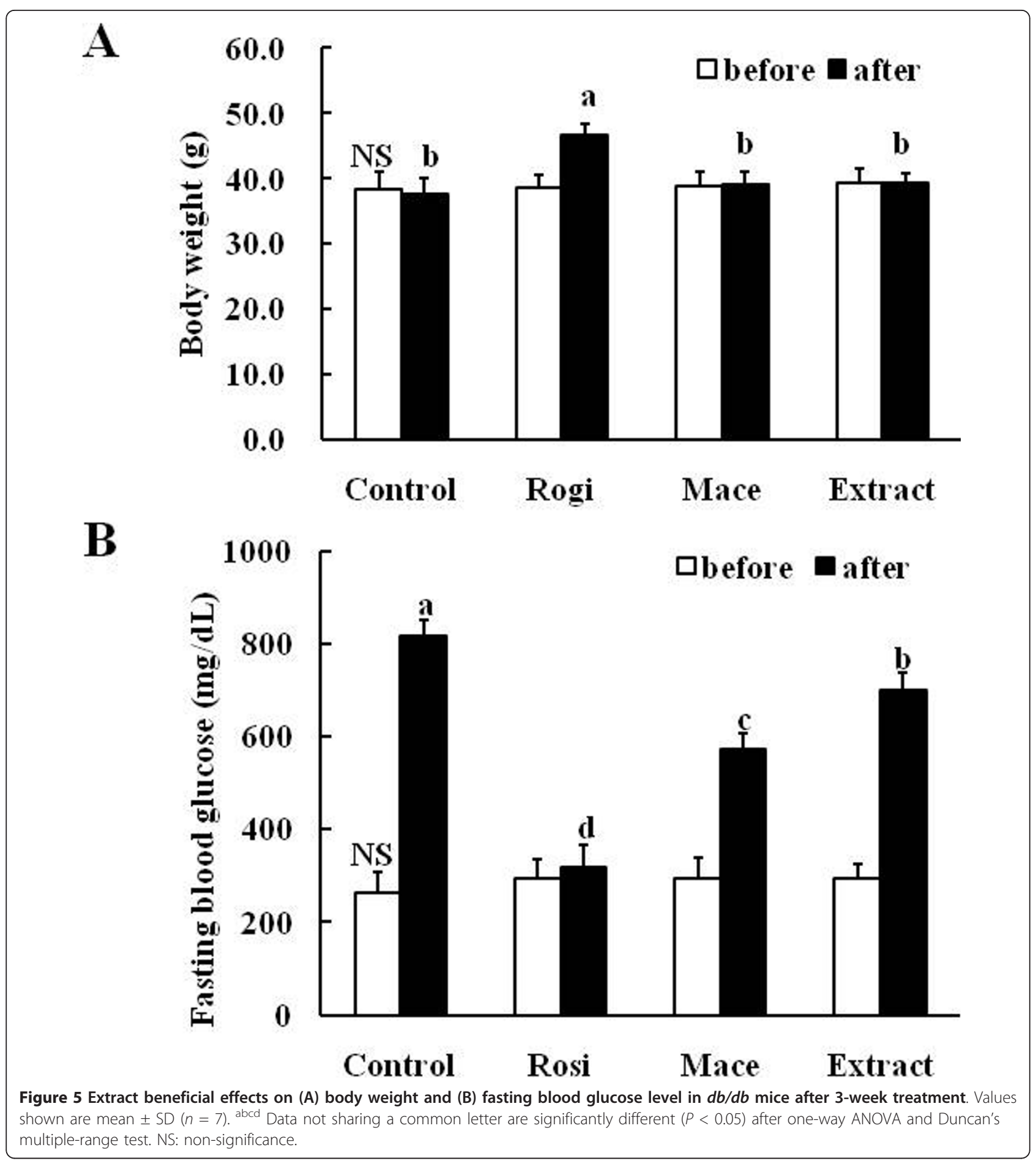

with an activity similar to troglitazone, and up-regulates the expression of PPAR $\gamma$ target genes such as aP2, LPL and PEPCK [15]. Therefore, the activity of PPAR $\gamma$ against may be due to Panax ginseng. Further studies are required to confirm this speculation.

Activation of AMPK enhances insulin sensitivity through increased glucose uptake and lipid oxidation in skeletal muscle and inhibition of glucose and lipid synthesis in the liver [20]. Metformin acts as an activator of AMPK in the liver and skeletal muscle [21]. The present study demonstrated that the extract activated AMPK in $\mathrm{C} 2 \mathrm{C} 12$ and induced increased expression of AMPK target genes. Ginsenoside Rh2 and Rg3, a red ginseng rich constituent, activates AMPK significantly in 


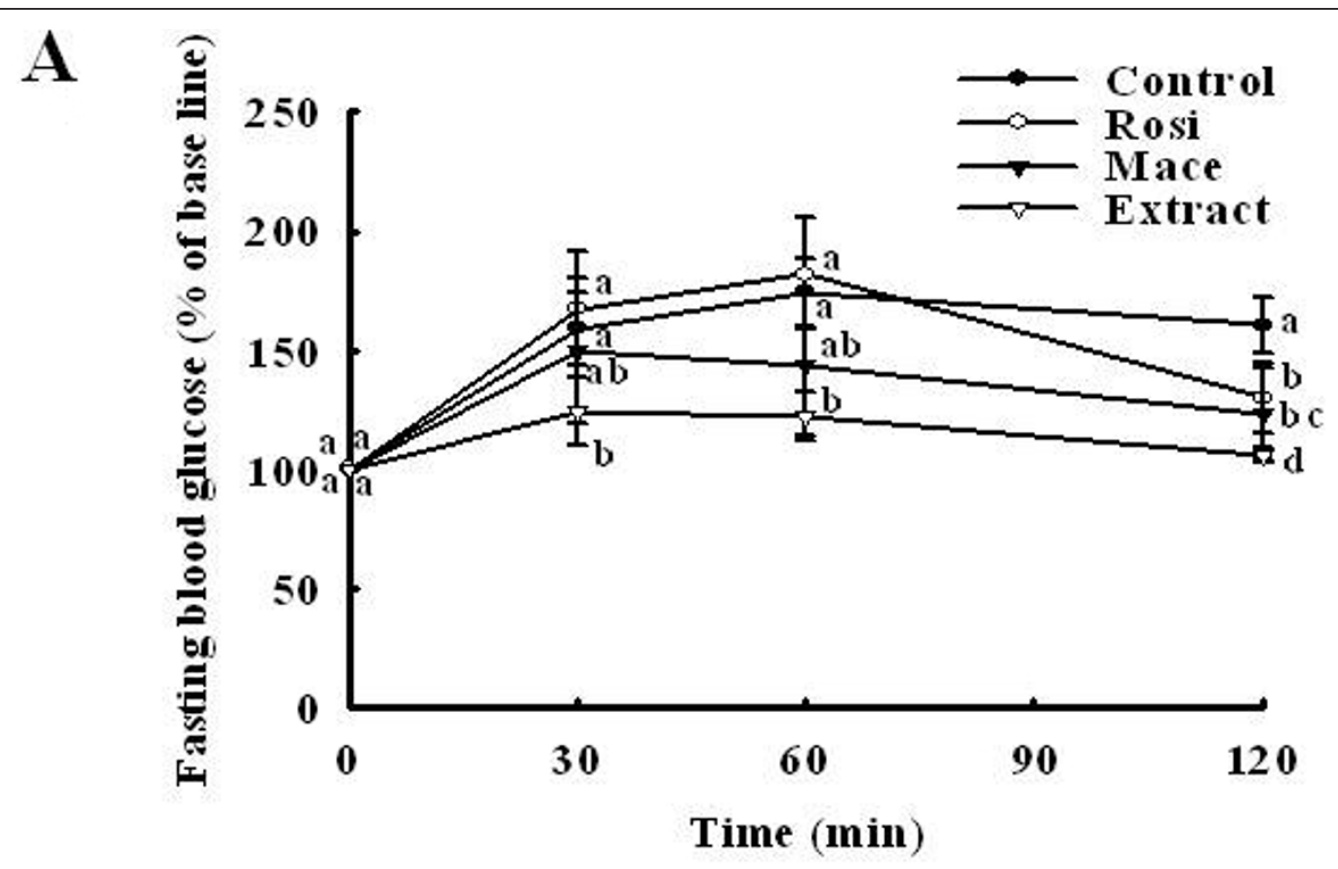

B
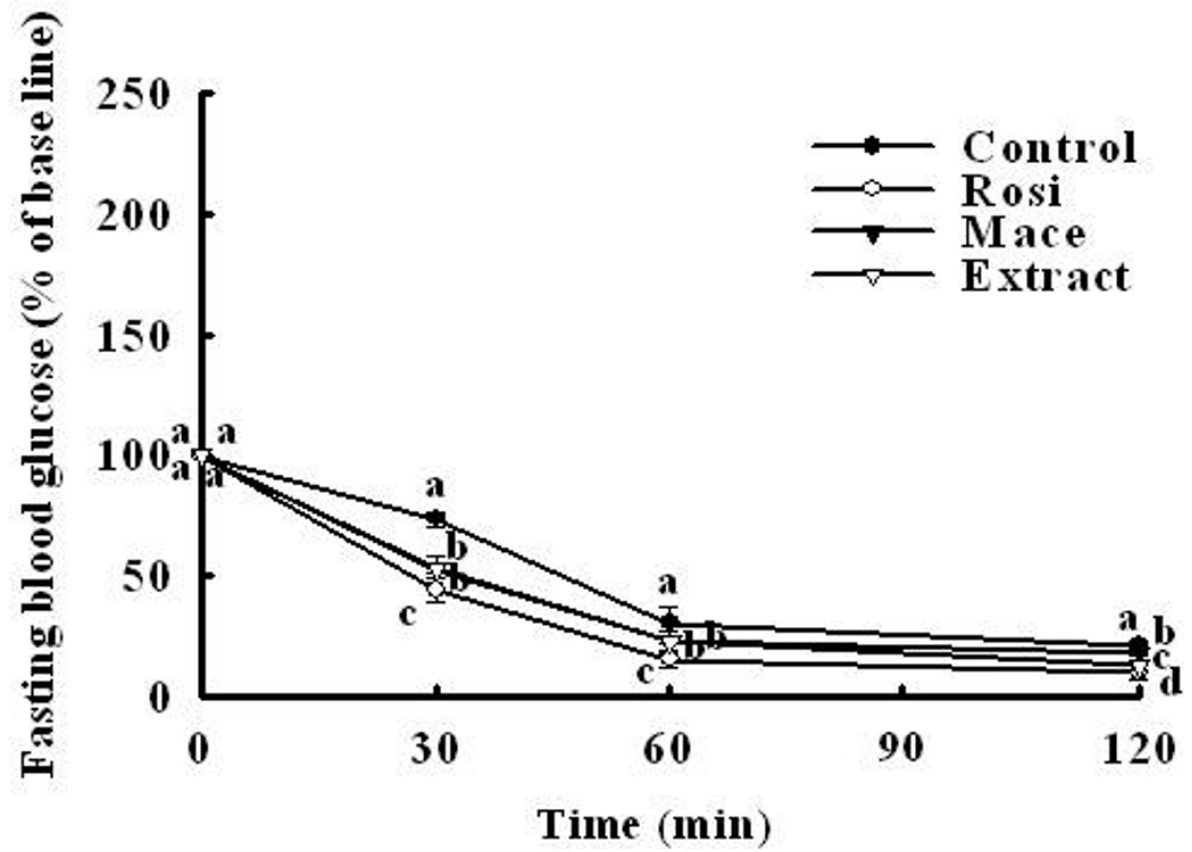

Figure 6 Extract improved (A) postprandial glucose and (B) insulin sensitivity in $\mathbf{d b} / \mathbf{d} \boldsymbol{b}$ mice. After a 12-hourfast, male mice (12 weeks-old) were intraperitoneally injected with glucose $(0.5 \mathrm{~g} / \mathrm{kg}$ body weight) and insulin ( 2 units $/ \mathrm{kg}$ body weight). The blood glucose concentration was then measured at the indicated times and was presented as a percentage of the glucose injection zero time. Values are mean \pm SD $(n=7)$. abcd Data not sharing a common letter are significantly different $(P<0.05)$ after one-way ANOVA and Duncan's multiple-range test.

3T3-L1 adipocytes and to contribute to antiobesity effects [22,23]. Further studies are required to characterize which herb activates AMPK.

Inflammatory cytokines and IKK attenuate insulin signaling through serine phosphorylation of IRS-1 [24]. High doses of salicylates, which block the IKKb activity, ameliorate hyperglycemia and insulin resistance in diabetes and obesity [25]. Our results showed that the extract effectively suppressed NFkB-dependent luciferase activity in TNF- $\alpha$-treated HepG2 cells and increased the IkB level, suggesting that the extract blocked the activation of the NF- $\kappa$ B pathways.

By activating c-Jun amino-terminal kinase (JNK), which induces insulin resistance in liver and skeletal 
Table 1 Effects of the extract on the plasma lipid profiles in $d b / d b$ mice

\begin{tabular}{lllll}
\hline & Control & Rosiglitazone & Macelignan & Extract \\
\hline FFAs (mmol/L) & $2.28 \pm 0.21^{\mathrm{a}}$ & $0.94 \pm 0.05^{\mathrm{c}}$ & $1.70 \pm 0.21^{\mathrm{b}}$ & $1.75 \pm 0.11^{\mathrm{b}}$ \\
Triglyceride $(\mathrm{mg} / \mathrm{dL})$ & $296.2 \pm 59.5^{\mathrm{a}}$ & $109.4 \pm 29.2^{\mathrm{c}}$ & $259.0 \pm 54.9^{\mathrm{ab}}$ & $217.9 \pm 34.9^{\mathrm{b}}$ \\
Total cholesterol $(\mathrm{mg} / \mathrm{dL})$ & $146.1 \pm 15.0^{\mathrm{b}}$ & $181.9 \pm 5.84^{\mathrm{a}}$ & $110.0 \pm 22.4^{c}$ & $119.4 \pm 3.41^{c}$ \\
\hline
\end{tabular}

${ }^{\mathrm{abc}}$ Data in the same row not sharing a common superscript indicate a significant difference $(P<0.05)$ between groups after one-way ANOVA and Duncan's multiple-range test; mean \pm SD $(n=7)$; FFAs: free fatty acids.

Table 2 Effects of the extract on concentrations of blood and plasma biomarkers in $d b / d b$ mice

\begin{tabular}{|c|c|c|c|c|c|}
\hline & $\mathrm{HbA}_{1 \mathrm{c}}(\%)$ & Insulin (ng/mL) & Glucagon (ng/mL) & C-peptide (ng/mL) & $\mathrm{I} / \mathrm{G}$ \\
\hline Control & $10.7 \pm 0.46^{a}$ & $1.48 \pm 0.89^{b}$ & $0.37 \pm 0.07^{a}$ & $3.12 \pm 0.73^{b}$ & $4.68 \pm 1.11^{b}$ \\
\hline Rosiglitaozne & $7.40 \pm 0.88^{c}$ & $3.43 \pm 1.05^{a}$ & $0.32 \pm 0.02^{a}$ & $4.76 \pm 1.09^{a}$ & $9.67 \pm 3.05^{\mathrm{ab}}$ \\
\hline Macelignan & $10.8 \pm 0.25^{a}$ & $1.52 \pm 0.12^{b}$ & $0.23 \pm 0.05^{b}$ & $4.14 \pm 0.35^{a b}$ & $6.74 \pm 1.31^{b}$ \\
\hline Extract & $9.3 \pm 0.80^{b}$ & $3.15 \pm 1.43^{a}$ & $0.21 \pm 0.02^{b}$ & $4.79 \pm 0.44^{a}$ & $14.2 \pm 7.55^{\mathrm{a}}$ \\
\hline
\end{tabular}

${ }^{\mathrm{abc}}$ Data in the same row not sharing a common superscript indicate a significant difference $(\mathrm{P}<0.05)$ between groups after one-way ANOVA and Duncan's multiple-range test; mean $\pm \mathrm{SD}(n=7) ; \mathrm{HbA}_{1 c}$ : blood glycosylated hemoglobin; I/G: ratio of insulin/glucagon.

muscle and inhibits beta cell function, ER stress induces the development of type 2 diabetes [26]. Thus, agents that alleviate ER stress may act as potent anti-diabetic agents. Chemical or biological compounds such as macelignan [27], chromium-phenylalanine [28], PBA (phenyl butyric acid) [29] or TUDCA (tauroursodeoxycholic acid) [30] or molecular chaperon have been shown to inhibit ER stress and enhance insulin sensitivity, thereby normalizing hyperglycemia. The present study found that the extract alleviated ER stress and efficiently suppressed ERSE-dependent transactivation in thapsigargin-treated HepG2 and expression of ER stress marker proteins. In future studies, we will determine the optimal combination ratio for this formulation and isolate its active fractions.

\section{Conclusion}

The aqueous extract of these seven hypoglycemic herbs demonstrated anti-diabetic effects on type 2 diabetes.

\begin{abstract}
Abbreviations
ACS: acyl-CoA synthetase; AICAR: aminoimidazole carboxamide ribonucleotide; AMPK: AMP-activated protein kinase; aP2: adipose fatty acidbinding protein 2; CPT-1: carnitine palmitoyltransferase-1; DMSO: Dimethylsulfoxide; ER: endoplasmic reticulum; ERSE: ER stress response element; FFAs: free fatty acids; elF: elongation initiation factor; GLP-1: glucagon-like peptide-1; $\mathrm{HbA}_{1}$ : blood glycosylated hemoglobin; HDLcholesterol: high density lipoprotein-cholesterol; HEK293: human embryonic kidney293; IKK: IKB kinase; IPGTT: intraperitoneal glucose tolerance test; IPITT: intraperitoneal insulin tolerance test; JNK: c-Jun N-terminal kinases; LPL: lipoprotein lipase; OAD: oral antidiabetic drug; PBA: phenyl butyric acid; PPAR: peroxisome proliferator-activated receptor; PPREs: PPAR-responsive elements; SD: standard deviation; TZD: thiazolidinedione
\end{abstract}

\section{Acknowledgements}

This research was supported by the Basic Science Research Program through the National Research Foundation of Korea (NRF) funded by the Ministry of Education, Science and Technology (331-2008-1-E-00036) and Pusan National University (Program Post-Doc 2009).

\section{Authors' contributions}

$\mathrm{MHJ}$ designed the study and wrote the manuscript. SIC prepared the aqueous extract from the herbs. JY conducted the in vivo experiments. YMK conducted the experiments in cultured cells. All authors read and approved the final version of the manuscript.

\section{Competing interests}

The authors declare that they have no competing interests.

Received: 14 October 2010 Accepted: 4 March 2011

Published: 4 March 2011

\section{References}

1. Chan JY, Leung PC, Che CT, Fung KP: Protective effects of an herbal formulation of Radix Astragali, Radix Codonopsis and Cortex Lycii on streptozotocin-induced apoptosis in pancreatic beta-cells: an implication for its treatment of diabetes mellitus. Phytother Res 2008, 22:190-196.

2. Colberg SR, Zarrabi L, Bennington L, Nakave A, Thomas SC, Swain DP, Sechrist SR: Postprandial walking is better for lowering the glycemic effect of dinner than pre-dinner exercise in type 2 diabetic individuals. $J$ Am Med Dir Assoc 2009, 10:394-397.

3. Yin J, Zhang H, Ye J: Traditional Chinese medicine in treatment of metabolic syndrome. Endocr Metab Immune Disord Drug Targets 2008, 8:99-111.

4. Bailey CJ, Day C: Traditional plant medicines as treatments for diabetes. Diabetes care 1989, 12:553-564.

5. Bansky D, Barolet R: Chinese Herbal Medicine Formulas and Strategies Seattle: Eastland Press; 1990, 3-14.

6. Li WL, Zheng HC, Bukuru J, De Kimpe N: Natural medicines used in the traditional Chinese medical system for therapy of diabetes mellitus. $J$ Ethnopharmacol 2004, 92(1):1-21.

7. Hui H, Tang G, Go VL: Hypoglycemic herbs and their action mechanisms. Chin Med 2009, 4:11.

8. Waisundara VY, Huang M, Hsu A, Huang D, Tan BK: Characterization of the anti-diabetic and antioxidant effects of Rehmannia Glutinosa in streptozotocin-induced diabetic wistarats. Am J Chin Med (Gard City N Y) 2008, 36:1083-1104.

9. Suneetha WJ, Krishnakantha TP: Cardamom extract as inhibitor of human platelet aggregation. Phytother Res 2005, 19:437-440.

10. Lee YM, Kim DK, Kim SH, Shin TY, Kim HM: Antianaphylactic activity of Poncirus trifoliata fruit extract. J Ethnopharmacol 1996, 54:77-84.

11. Yamahara J, Yamada T, Kitani T, Naitoh Y, Fujimura H: Antianoxic action and active constituents of evodiae fructus. Chem Pharm Bull (Tokyo) 1989, 37:1820-1822.

12. Korea Food \& Drug Administration, Republic of Korea: The Korean Pharmacopeia. Seoul; 2008, 942-974. 
13. Chung JY, Choo JH, Lee MH, Hwang JK: Anticariogenic activity of macelignan isolated from Myristica fragrans (nutmeg) against Streptococcus mutants. Phytomedicine 2006, 13:261-266.

14. Choi BH, Ahn IS, Kim YH, Park JW, Lee SY, Hyun CK, Do MS: Berberine reduces the expression of adipogenic enzymes and inflammatory molecules of 3T3-L1 adipocyte. Exp Mol Med 2006, 38:599-605.

15. Han KL, Jung MH, Sohn JH, Hwang JK: Ginsenoside 20(S)-protopanaxatriol (PPT) activates peroxisome proliferator-activated receptor gamma (PPARgamma) in 3T3-L1 adipocytes. Biol Pharm Bull 2006, 29:110-113.

16. Fonseca SG, Burcin M, Gromada J, Urano F: Endoplasmic reticulum stress in beta-cells and development of diabetes. Curr Opin Pharmacol 2009, 9:763-770

17. Sheng X, Zhang Y, Gong Z, Huang C, Zang YQ: Improved insulin resistance and lipid metabolism by cinnamon extract through activation of peroxisome proliferator-activated receptors. PPAR Res 2008, 581348:1-9.

18. Watkins SM, Reifsnyder PR, Pan HJ, German JB, Leiter EH: Lipid metabolome-wide effects of the PPARgamma agonist rosiglitazone. J Lipid Res 2002, 43:1809-1817.

19. Shang W, Yang Y, Jiang B, Jin H, Zhou L, Liu S, Chen M: Ginsenoside Rb1 promotes adipogenesis in 3T3-L1 cells by enhancing PPARgamma2 and C/EBPalpha gene expression. Life Sci 2007, 80:618-625.

20. Yamauchi T, Kamon J, Minokoshi Y, Ito Y, Waki H, Uchida S, Yamashita S, Noda M, Kita S, Ueki K, Eto K, Akanuma Y, Froguel P, Foufelle F, Ferre P, Carling D, Kimura S, Nagai R, Kahn BB, Kadowaki T: Adiponectin stimulates glucose utilization and fatty-acid oxidation by activating AMP-activated protein kinase. Nat Med 2002, 8:1288-1295.

21. Viollet B, Foretz M, Guigas B, Horman S, Dentin R, Bertrand L, Hue L, Andreelli F: Activation of AMP-activated protein kinase in the liver: a new strategy for the management of metabolic hepatic disorders. J Physiol 2006, 574:41-53.

22. Hwang J, Kim SH, Lee MS, Kim SH, Yang HJ, Kim MJ, Kim HS, Ha J, Kim MS, Kwon DY: Anti-obesity effects of ginsenoside Rh2 are associated with the activation of AMPK signaling pathway in 3T3-L1 adipocyte. Biochem Biophys Res Commun 2007, 364:1002-1008.

23. Hwang JT, Lee MS, Kim HJ, Sung MJ, Kim HY, Kim MS, Kwon DY: Antiobesity effect of ginsenoside Rg3 involves the AMPK and PPARgamma signal pathways. Phytother Res 2009, 23:262-266.

24. Gao Z, Zuberi A, Quon MJ, Dong Z, Ye J: Aspirin inhibits serine phosphorylation of insulin receptor substrate 1 in tumour necrosis factor-treated cells through targeting multiple serine kinases. J Biol Chem 2003, 278:24944-24950

25. Zheng L, Howell SJ, Hatala DA, Huang K, Kern TS: Salicylate-based antiinflammatory drugs inhibit the early lesion of diabetic retinopathy. Diabetes 2007, 56:337-345.

26. Kaneto H, Matsuoka TA, Nakatani Y, Kawamori D, Miyatsuka T, Matsuhisa M, Yamasaki Y: Oxidative stress, ER stress, and the JNK pathway in type 2 diabetes. J Mol Med 2005, 83:429-439.

27. Han KL, Choi JS, Lee JY, Song J, Joe MK, Jung MH, Hwang JK: Therapeutic potential of peroxisome proliferators-activated receptor-alpha/gamma dual agonist with alleviation of endoplasmic reticulum stress for the treatment of diabetes. Diabetes 2008, 57:737-745.

28. Sreejayan N, Dong F, Kandadi MR, Yang X, Ren J: Chromium alleviates glucose intolerance, insulin resistance, and hepatic ER stress in obese mice. Obesity 2008, 16:1331-1337.

29. Ozcan U, Yilmaz E, Ozcan L, Furuhashi M, Vaillancourt E, Smith RO, Görgün CZ, Hotamisligil GS: Chemical chaperones reduce ER stress and restore glucose homeostasis in a mouse model of type 2 diabetes. Science 2006, 313:1137-1140.

30. Xie Q, Khaoustov VI, Chung CC, Sohn J, Krishnan B, Lewis DE, Yoffe B: Effect of tauroursodeoxycholic acid on endoplasmic reticulum stress-induced caspase-12 activation. Hepatology 2002, 36:592-601.

doi:10.1186/1749-8546-6-10

Cite this article as: Yeo et al:: Effects of a multi-herbal extract on type 2 diabetes. Chinese Medicine 2011 6:10.

\section{Submit your next manuscript to BioMed Central and take full advantage of:}

- Convenient online submission

- Thorough peer review

- No space constraints or color figure charges

- Immediate publication on acceptance

- Inclusion in PubMed, CAS, Scopus and Google Scholar

- Research which is freely available for redistribution

Submit your manuscript at www.biomedcentral.com/submit
Biomed Central 